\title{
An updated meta-analysis evaluating limb management after total knee arthroplasty - what is the optimal method?
}

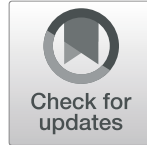

Hai-yang Wang, Guang-shu Yu, Jie-hui Li, Shou-xiong Zhang and Yan-bin Lin*

\begin{abstract}
Purpose: Postoperative knee flexion protocol has been widely recognized as a highly attractive, simple, and costeffective tactic to improve patient's outcomes after primary total knee arthroplasty (TKA). However, optimal knee position and duration of knee flexion are still controversial. The purpose of this meta-analysis was to compare the effectiveness of different postoperative knee flexion protocols, as an aid to find out optimal limb management strategy following TKA.

Methods: We conducted a meta-analysis to identify the available and relevant randomized controlled trials (RCTs) with regard to the influence of different postoperative knee positions on clinical outcomes after primary TKA in electronic databases, including PubMed, EMBASE, the Cochrane Library, Web of Science, CNKI, Wanfang Med Online, and VIP, up to May 2018. In this meta-analysis, three major subgroups based on diverse postoperative knee flexion protocols were considered: long-term $(\geq 24 \mathrm{~h})$ high flexion $\left(>30^{\circ}\right)$, short term $(<24 \mathrm{~h})$ high flexion $\left(>30^{\circ}\right)$, and long-term $\left(\geq 24 \mathrm{~h}\right.$ ) mild flexion $\left(\leq 30^{\circ}\right)$. The statistical analysis was performed using the Review Manager (RevMan) version 5.3 software.
\end{abstract}

Results: A total of 16 trials were finally included in this meta-analysis. The result of subgroup analysis indicated that keeping the knee in high flexion $\left(>30^{\circ}\right)$ postoperatively for a long time $(\geq 24 \mathrm{~h}$ ) significantly reduced total blood loss $(P<0.00001)$, hidden blood loss $(P<0.00001)$, and transfusion requirements $(P=0.003)$ and led to a significant improvement in range of motion (ROM) at 1 week after operation $(P<0.00001)$; keeping the knee in high flexion $\left(>30^{\circ}\right)$ postoperatively for a short time $(<24 \mathrm{~h})$ significantly reduced total blood loss $(P=0.006)$ and hidden blood loss $(P<0.00001)$ but not significantly improved ROM at 1 week after operation $(P=0.34)$ and reduced transfusion requirements $(P=0.62)$; and keeping the knee in mild flexion $\left(\leq 30^{\circ}\right)$ postoperatively for a long time $(\geq 24 \mathrm{~h})$ significantly reduced total blood loss $(P=0.02)$ and transfusion requirements $(P=0.02)$ and improved ROM at 1 week after operation $(P<0.00001)$ but not significantly reduced hidden blood loss $(P=0.11)$. Furthermore, there was no significant difference with respect to the rates of wound-related infection and DVT between the three knee flexion subgroups.

Conclusions: This meta-analysis showed that the long-term $\left(\geq 24 \mathrm{~h}\right.$ ) high flexion $\left(>30^{\circ}\right)$ protocol could be an optimal limb management to reduce blood loss and blood transfusion requirements and facilitate early postoperative rehabilitation exercises in patients after primary TKA without increasing in complication rate.

Keywords: Total knee arthroplasty, Mild flexion, High flexion, Duration of flexion, Blood loss, Range of motion

\footnotetext{
* Correspondence: Lyanb32@163.com

Department of Orthopedics, Fuzhou the Second Hospital Affiliated to

Xiamen University, 47 Shangteng Road, Fuzhou 350,007, Fujian, People's

Republic of China
}

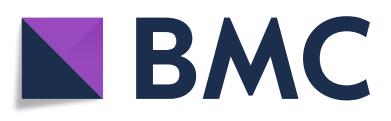

(c) The Author(s). 2019 Open Access This article is distributed under the terms of the Creative Commons Attribution 4.0 International License (http://creativecommons.org/licenses/by/4.0/), which permits unrestricted use, distribution, and reproduction in any medium, provided you give appropriate credit to the original author(s) and the source, provide a link to the Creative Commons license, and indicate if changes were made. The Creative Commons Public Domain Dedication waiver (http://creativecommons.org/publicdomain/zero/1.0/) applies to the data made available in this article, unless otherwise stated. 


\section{Introduction}

Total knee arthroplasty (TKA) is an effective surgical treatment method for patients with moderate to severe arthritis who has not responded to medical management [1]. However, surgical interventions can be associated with substantial blood loss, which may result in anemia and require postoperative blood transfusion. Previous studies reported blood loss related to TKA can exceed $1000 \mathrm{~mL}$ [2], approximately $20 \%$ of the body's total blood volume [3], and the rate of blood transfusion following TKA can be as high as $40 \%[4,5]$. Allogenic blood transfusion could not only increase the likelihood of transmission of disease, immunological reactions, transfusion-associated circulatory overload, and even death $[6,7]$ but could also prolong the duration of hospital stay and increase medical costs $[8,9]$. Most importantly, blood loss also affects the recovery of knee range of motion (ROM), but the restoration of a satisfactory ROM is crucial for an optimal result, and slight improvements in maximum flexion can have profound effects on functional capability [10].

Thus, various prevention agents and techniques have been proposed to reduce postoperative blood loss and subsequent transfusion requirements, such as various drainage protocols, tourniquet use, pharmacological methods (fibrin spray, adrenaline, and tranexamic acid), postoperative cryotherapy and knee positioning, and invasive and computer-aided surgical techniques [11-18]. Among these, keeping the knee in flexion postoperatively has been identified as a highly simple and cost-effective way to reduce blood loss and transfusion requirements and increase ROM after primary TKA [19-26]. Nevertheless, there are opposite opinions about the availability and safety of postoperative knee positioning on outcomes after TKA [27-29].

Two previous meta-analyses have compared the impact of flexion versus extension of knee position on outcomes after TKA and demonstrated that positioning the knee in flexion was associated with significantly lesser total blood loss, lesser hidden blood loss, decreased need for blood transfusion, and better ROM in the early postoperative period [7, 30]. Thus far, there is no clear consensus upon whether it is accurate knee position and duration of knee flexion which conduces most to the benefits seen with postoperative knee flexion strategies. A previous systematic

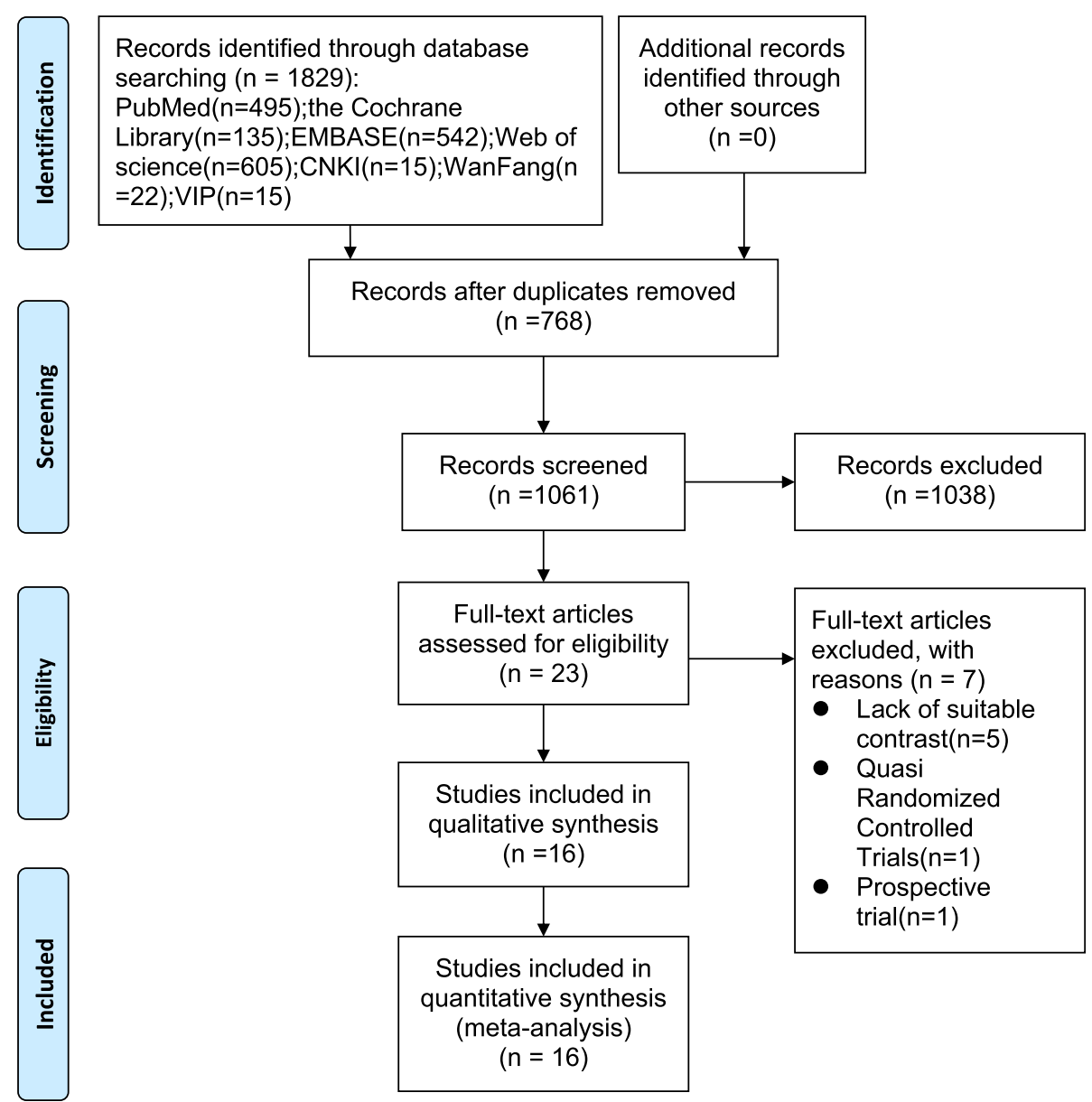

Fig. 1 The PRISMA flow diagram detailing our literature search 
review has shown that keeping the knee in flexion postoperatively for $48-72 \mathrm{~h}$ appears to be effective in reducing blood loss and increasing ROM following TKA, and the application of shorter (6-24h) post-operative knee flexion strategies reveals no benefit [31]. However, recently, three high-quality randomized controlled trials (RCTs) reported knee flexion for 6-24h could significantly reduce blood loss and the need for blood transfusion compared with knee extension following TKA $[20,25,26]$. A recent updated meta-analysis of RCTs has demonstrated that compared with knee high flexion $\left(\geq 60^{\circ}\right)$, mild flexion $\left(<60^{\circ}\right)$ positioning is significantly beneficial with hidden blood loss after TKA and high flexion $\left(\geq 60^{\circ}\right)$ positioning is superior to mild flexion $\left(<60^{\circ}\right)$ positioning in reducing blood transfusion requirements and improving ROM following TKA [32], but the study did not perform subgroup analysis based on the time (6-72 h) of knee flexion, which may lower the accuracy of conclusions. Although the results of new RCTs by De Fine et al [33] suggested that no significant differences related to blood loss reduction, blood transfusion diminution, and ROM improvement after TKA were found between the high flexion $\left(70^{\circ}\right)$ and mild flexion $\left(30^{\circ}\right)$ group, this study lacked a control group of knee extension and sufficient sample size. In 2018, one new RCT has been published, with seemingly mixed results [26]. In addition, six RCTs [34-39] written in Chinese were not part of previous reviews, which would have brought about statistical bias and publication bias. Furthermore, because of the limited amount of included studies, publication bias failed to be assessed exactly in previous reviews. Hence, we believe those reviews need to be renewed again.

The purpose of the current meta-analysis was to compare the effectiveness and safety of three different knee flexion protocols in patients following primary TKA: long-term $(\geq 24 \mathrm{~h})$ high flexion $\left(>30^{\circ}\right)$, short-term $(<24$ h) high flexion $\left(>30^{\circ}\right)$, and long-term $(\geq 24 \mathrm{~h})$ mild flexion $\left(\leq 30^{\circ}\right)$, with regard to total blood loss, hidden blood loss, blood transfusion requirement, ROM at 1 week after operation, deep vein thrombosis (DVT), and wound-related infection, and to eventually find out optimal limb management strategy following TKA.

\section{Methods}

\section{Search strategies}

This study was performed in accordance with the 2009 PRISMA (Preferred Reporting Items for Systematic Reviews and Meta-Analysis) guidelines [40]. A comprehensive literature search was implemented in PubMed, EMBASE, the Cochrane Library, Web of Science, CNKI, Wanfang Med Online, and VIP for RCTs (from the earliest available records to May 1, 2018), using the keywords and their combinations: total knee arthroplasty, TKA, total knee replacement, TKR, knee position, leg position, limb position, extension, flexion. All studies published in English

Table 1 Key characteristics of RCTs included in the meta-analysis

\begin{tabular}{|c|c|c|c|c|c|c|c|c|c|c|c|c|c|c|}
\hline \multirow[t]{3}{*}{ Studies } & \multirow[t]{3}{*}{ Type } & \multirow{3}{*}{$\begin{array}{l}\text { Study } \\
\text { period }\end{array}$} & \multirow{2}{*}{\multicolumn{2}{|c|}{ Sample size }} & \multirow{2}{*}{\multicolumn{2}{|c|}{ Mean age (mean) }} & \multirow{2}{*}{\multicolumn{2}{|c|}{ Gender (F/M) }} & \multicolumn{6}{|c|}{ Disease } \\
\hline & & & & & & & & & \multicolumn{3}{|c|}{ Flexion } & \multicolumn{3}{|c|}{ Extension } \\
\hline & & & Flexion & Extension & Flexion & Extension & Flexion & Extension & $\mathrm{OA}$ & RA & $\mathrm{PO}$ & $\overline{\mathrm{OA}}$ & RA & $\mathrm{PO}$ \\
\hline Ong 2003 [42] & $\mathrm{RCT}$ & 2000 & 20 & 20 & 71 & 74 & $12 / 8$ & $13 / 7$ & 20 & 0 & 0 & 20 & 0 & 0 \\
\hline Ma 2008 [27] & $\mathrm{RCT}$ & 2005-2006 & 49 & 46 & 71 & 70.6 & $25 / 24$ & $22 / 24$ & 46 & 3 & 0 & 42 & 4 & 0 \\
\hline Li 2017 [24] & $\mathrm{RCT}$ & 2011-2012 & 54 & 54 & 72.6 & 71.7 & $43 / 11$ & $46 / 8$ & 47 & 7 & 0 & 44 & 10 & 0 \\
\hline Liu 2015 [22] & $\mathrm{RCT}$ & 2013-2014 & 50 & 50 & 73.1 & 72.4 & $34 / 16$ & $32 / 18$ & 50 & 0 & 0 & 50 & 0 & 0 \\
\hline Zeng 2018 [26] & $\mathrm{RCT}$ & 2016-2017 & 30 & 30 & 68.78 & 69.68 & $21 / 9$ & $20 / 10$ & NA & NA & 0 & NA & NA & 0 \\
\hline Panni 2014 [25] & $\mathrm{RCT}$ & 2012-2013 & 50 & 50 & 69 & 61 & $38 / 12$ & $40 / 10$ & 50 & 0 & 0 & 50 & 0 & 0 \\
\hline Yang 2015 [23] & RCT & 2012-2014 & 23 & 23 & 73.6 & 72.5 & $11 / 12$ & $10 / 13$ & 23 & 0 & 0 & 23 & 0 & 0 \\
\hline Antinolfi 2014 [28] & $\mathrm{RCT}$ & NA & 20 & 20 & 73 & 70.7 & $13 / 7$ & $10 / 10$ & 20 & 0 & 0 & 20 & 0 & 0 \\
\hline Napier 2014 I [20] & $\mathrm{RCT}$ & 2003-2004 & 86 & 89 & 70.4 & 71 & $64 / 22$ & $58 / 32$ & 78 & 5 & 3 & 78 & 6 & 5 \\
\hline Napier 2014 || [20] & $\mathrm{RCT}$ & 2006 & 134 & 140 & 68.9 & 70.9 & $83 / 51$ & $101 / 39$ & 131 & 3 & 0 & 137 & 3 & 0 \\
\hline Li 2012 [21] & $\mathrm{RCT}$ & 2008 & 55 & 55 & 71 & 70 & $40 / 15$ & $38 / 17$ & 47 & 8 & 0 & 46 & 9 & 0 \\
\hline Zhao 2014 [36] & $\mathrm{RCT}$ & $2011-2013$ & 111 & 102 & 64.2 & 63.2 & $111 / 0$ & $102 / 0$ & 111 & 0 & 0 & 102 & 0 & 0 \\
\hline Shen 2016 [38] & $\mathrm{RCT}$ & $2013-2016$ & 90 & 90 & 61.9 & 62.3 & $54 / 36$ & $53 / 37$ & 90 & 0 & 0 & 90 & 0 & 0 \\
\hline Hu 2013 [35] & $\mathrm{RCT}$ & 2010-2012 & 65 & 68 & 67.7 & 67.8 & $65 / 0$ & $68 / 0$ & 65 & 0 & 0 & 68 & 0 & 0 \\
\hline Li 2016 [39] & $\mathrm{RCT}$ & 2015 & 50 & 50 & 63.1 & 62.4 & $16 / 34$ & $18 / 32$ & 50 & 0 & 0 & 50 & 0 & 0 \\
\hline Guo 2013 [37] & $\mathrm{RCT}$ & 2012 & 30 & 30 & 72 & 71 & $23 / 7$ & $22 / 8$ & 30 & 0 & 0 & 30 & 0 & 0 \\
\hline Peng 2016 I [34] & $\mathrm{RCT}$ & 2014-2015 & 30 & 30 & 73.5 & 73.0 & $18 / 12$ & $19 / 11$ & 30 & 0 & 0 & 30 & 0 & 0 \\
\hline Peng 2016 II [34] & RCT & 2014-2015 & 30 & 30 & 74.1 & 73.0 & $17 / 13$ & $19 / 11$ & 30 & 0 & 0 & 30 & 0 & 0 \\
\hline
\end{tabular}


and Chinese were considered for inclusion. Subsequently, a manual search of references of those studies also was conducted by authors for any possibly relevant studies.

\section{Inclusive and exclusive criteria}

Included studies were considered eligible by two authors if they met the following inclusion criteria: (1) RCTs; (2) comparison of knee positioning in flexion versus extension after primary unilateral TKA; (3) trials providing data related to outcomes including total blood loss, hidden blood loss, blood transfusion requirement, ROM at 1 week after operation, DVT, and wound-related infection. Exclusion criteria included review articles, non-randomized trials, quasi-randomized trials, articles involving bilateral TKA and revision knee arthroplasty, and articles with insufficient outcome data. In cases of discrepancy, a consensus was reached through discussion among authors.

\section{Primary and secondary outcomes}

The primary outcomes included total blood loss, hidden blood loss, and transfusion requirement. Secondary outcomes included ROM at 1 week after operation, DVT, and wound-related infection.

\section{Data extraction}

Two authors independently extracted relevant data from each eligible study using a standard data extraction worksheet. Discrepancies in opinion between authors were resolved by discussion and a third author was consulted if necessary. The data extracted included the first author, year of publication, country of origin, participant characteristics, methodological characteristics, type of intervention, surgical procedures, and measured outcomes. If the trials had multiple comparisons, we extracted only the information and data of interest reported in the original trials. We also attempted to contact the corresponding authors of primary studies to make sure the information was integrated and request missing data.

\section{Quality assessment and risk of bias}

The methodological quality of the included RCTs was evaluated independently and carefully by two authors based on the Cochrane Handbook for Systematic Reviews of Interventions, version 5.1.0 (http://handbook. cochrane.org/). The following eight-item scales were assessed: random sequence generation (selection bias), allocation concealment (selection bias), blinding of the participants and personnel (performance bias), blinding

Table 2 Study intervention protocol of RCTs included in the meta-analysis

\begin{tabular}{|c|c|c|c|c|c|c|c|c|c|c|c|c|}
\hline \multirow[t]{3}{*}{ Studies } & \multirow[t]{3}{*}{ Country } & \multicolumn{5}{|c|}{ Intervention method } & \multirow[t]{3}{*}{ Approach } & \multirow[t]{3}{*}{ Tourniquet } & \multirow[t]{3}{*}{ Drain } & \multirow[t]{3}{*}{ TXA } & \multirow{3}{*}{$\begin{array}{l}\text { Prophylactic } \\
\text { anticoagulation }\end{array}$} & \multirow[t]{3}{*}{$\pi$} \\
\hline & & \multicolumn{3}{|l|}{ Flexion } & \multicolumn{2}{|c|}{ Extension } & & & & & & \\
\hline & & Knee & Hip & $\overline{\text { Time }}$ & Knee & Hip & & & & & & \\
\hline Ong 2003 [42] & the UK & $70^{\circ}$ & $35^{\circ}$ & $6 \mathrm{~h}$ & $\mathrm{FE}$ & $0^{\circ}$ & NA & Yes & Yes & NA & Enoxaparin or aspirin & $8 \mathrm{~g} / \mathrm{dl}$ \\
\hline Ma 2008 [27] & Australia & $70^{\circ}$ & $70^{\circ}$ & $24 \mathrm{~h}$ & $\mathrm{FE}$ & $0^{\circ}$ & MP & NA & Yes & NA & Enoxaparin $20 \mathrm{mg}$ & NA \\
\hline Li 2017 [24] & China & $<30^{\circ}$ & LE-25 & $72 \mathrm{~h}$ & $\mathrm{FE}$ & LE-25 & NA & Yes & Yes & NA & LMWH & $8 \mathrm{~g} / \mathrm{dl}$ \\
\hline Liu 2015 [22] & China & $45^{\circ}$ & $45^{\circ}$ & $48 \mathrm{~h}$ & $\mathrm{FE}$ & NA & MP & No & No & NA & Enoxaparin 40 mg & $8 \mathrm{~g} / \mathrm{dl}$ \\
\hline Zeng 2018 [26] & China & $90-60^{\circ}$ & NA & $24 \mathrm{~h}$ & $\mathrm{FE}$ & NA & MP & Yes & Yes & Yes & LMWH & $7 \mathrm{~g} / \mathrm{dl}$ \\
\hline Panni 2014 [25] & Italy & $90^{\circ}$ & $45^{\circ}$ & $6 \mathrm{~h}$ & $\mathrm{FE}$ & NA & MP & Yes & Yes & Yes & 4000 IU LMWH & $8 \mathrm{~g} / \mathrm{dl}$ \\
\hline Yang 2015 [23] & China & $60^{\circ}$ & $60^{\circ}$ & $48 \mathrm{~h}$ & $\mathrm{FE}$ & NA & MP & No & Yes & Yes & LMWH & $9 \mathrm{~g} / \mathrm{d}$ \\
\hline Antinolfi 2014 [28] & Italy & $90-50^{\circ}$ & NA & $6 \mathrm{~h}$ & $\mathrm{FE}$ & NA & MIP & Yes & Yes & NA & 4000 IU LMWH & NA \\
\hline Napier 2014 | [20] & the UK & $120^{\circ}$ & NA & $6 \mathrm{~h}$ & $\mathrm{FE}$ & NA & MP & Yes & No & No & Aspirin $150 \mathrm{mg}$ & $7 \mathrm{~g} / \mathrm{dl}$ \\
\hline Napier 2014 II [20] & the UK & $120^{\circ}$ & NA & $6 \mathrm{~h}$ & $\mathrm{FE}$ & NA & MP & Yes & No & No & Aspirin $150 \mathrm{mg}$ & $7 \mathrm{~g} / \mathrm{dl}$ \\
\hline Li 2012 [21] & China & $30^{\circ}$ & $30^{\circ}$ & $72 \mathrm{~h}$ & $\mathrm{FE}$ & $30^{\circ}$ & MV & No & No & NA & LMWH & $9 \mathrm{~g} / \mathrm{dl}$ \\
\hline Zhao 2014 [36] & China & $30^{\circ}$ & $45^{\circ}$ & $24 \mathrm{~h}$ & $\mathrm{FE}$ & $0^{\circ}$ & MP & Yes & Yes & NA & Rivaroxaban (10 mg/d) & $9 \mathrm{~g} / \mathrm{dl}$ \\
\hline Shen 2016 [38] & China & $70^{\circ}$ & $45^{\circ}$ & $12 \mathrm{~h}$ & $\mathrm{FE}$ & $0^{\circ}$ & NA & NA & Yes & NA & NA & NA \\
\hline Hu 2013 [35] & China & $70^{\circ}$ & $45^{\circ}$ & $12 \mathrm{~h}$ & $\mathrm{FE}$ & $0^{\circ}$ & NA & Yes & Yes & NA & Rivaroxaban(10 mg/d) & NA \\
\hline Li 2016 [39] & China & $45^{\circ}$ & $45^{\circ}$ & $48 \mathrm{~h}$ & $\mathrm{FE}$ & NA & MP & Yes & Yes & NA & Enoxaparin $0.4 \mathrm{ml}$ & $7 \mathrm{~g} / \mathrm{dl}$ \\
\hline Guo 2013 [37] & China & $70^{\circ}$ & $30^{\circ}$ & $6 \mathrm{~h}$ & $\mathrm{FE}$ & $0^{\circ}$ & MP & Yes & Yes & NA & Rivaroxaban (10 mg/d) & $8 \mathrm{~g} / \mathrm{dl}$ \\
\hline Peng 2016 | [34] & China & $30^{\circ}$ & $30^{\circ}$ & $72 \mathrm{~h}$ & $\mathrm{FE}$ & $30^{\circ}$ & MP & Yes & Yes & NA & Rivaroxaban(10 mg/d) & NA \\
\hline Peng 2016 || [34] & China & $60^{\circ}$ & $30^{\circ}$ & $72 \mathrm{~h}$ & $\mathrm{FE}$ & $30^{\circ}$ & MP & Yes & Yes & NA & Rivaroxaban (10 mg/d) & NA \\
\hline
\end{tabular}

Abbreviations: $L E-25$ leg elevated $25 \mathrm{~cm}, 90-60^{\circ} 90^{\circ}$ flexion position for the first $12 \mathrm{~h}$ and $60^{\circ}$ flexion position for the next $12 \mathrm{~h}, 90-50^{\circ} 90^{\circ}$ flexion position for the first $3 \mathrm{~h}$ and $50^{\circ}$ flexion position for the next $3 \mathrm{~h}$, FE full extension, NA not available, MP medial parapatellar approach, MIP modified Insallr approach, MV midvastus approach, $L M W H$ low molecular weight heparin, $T X A$ tranexamic acid, $T$ transfusion trigger 
of outcome assessments (detection bias), selective reporting (reporting bias), incomplete outcome data (attrition bias), and other biases. Each of the items needed to be measured as "Yes" (low risk of bias), "No" (high risk of bias), or "Unclear" (unclear risk of bias). The risk of bias summary and risk of bias graph were obtained using Review Manager (RevMan), version 5.3 (The Nordic Cochrane Centre, The Cochrane Collaboration, 2009, Copenhagen, Denmark). Disagreements were also settled down by discussion between the two authors.

\section{Statistical analysis}

The statistical analysis was performed with the help of Review Manager (RevMan), version 5.3 (The Nordic Cochrane Centre, The Cochrane Collaboration, 2009, Copenhagen, Denmark), and $P$ value $<0.05$ was regarded as statistically significant. For continuous variables, such as total blood loss, hidden blood loss, and range of motion, mean difference (MD) and 95\% confidence interval $(\mathrm{CI})$ were calculated. Dichotomous variables such as transfusion requirement, DVT, and wound-related infection were evaluated using risk difference (RD) with a 95\% confidence interval (CI). Statistical heterogeneity was primary assessed using the $I^{2}$ value and chi-square test. If the $I^{2}<50 \%$ or $P>0.05$, the heterogeneity might be unconsidered and a fixed effects model was adopted in order to evaluate the outcomes. If $I^{2}$ was between $50 \%$ and $100 \%$, or if $P<0.05$, it may show substantial heterogeneity. We used a random effects model to assess these outcomes. To precisely evaluate the influence of different postoperative degree and duration of knee flexion on patient's outcomes after TKA, we defined short term as flexing $<24 \mathrm{~h}$, long term as flexing $\geq 24 \mathrm{~h}$, high flexion as $>30^{\circ}$, and mild flexion as $\leq 30^{\circ}[21,24]$ and created three major subgroups: long-term high flexion groups, short-term high flexion groups, and long-term mild flexion groups, respectively. In addition, we investigated publication bias by funnel plots when the number of trials reporting the primary outcomes was ten or more [41].

\section{Results}

Study selection and characteristics of selected studies

A total of 1829 relevant studies were initially identified from electronic journals databases. After removal of duplicates, 1061 studies were available for assessing titles and abstracts for eligibility. Of these, 23 articles were then evaluated for full-text articles. After reading the full text of 23 remaining studies in detail, we eventually identified 16 articles [20-28, 34-39, 42] met the inclusive criteria. Among these, the article by Napier et al. [20] has two RCTs and the article by Peng et al. [34] has multiple comparisons. The PRISMA flow diagram detailing our literature search is illustrated in Fig. 1. All selected studies were in English or Chinese and were published between 2003 and 2018. The key characteristics of RCTs included in the

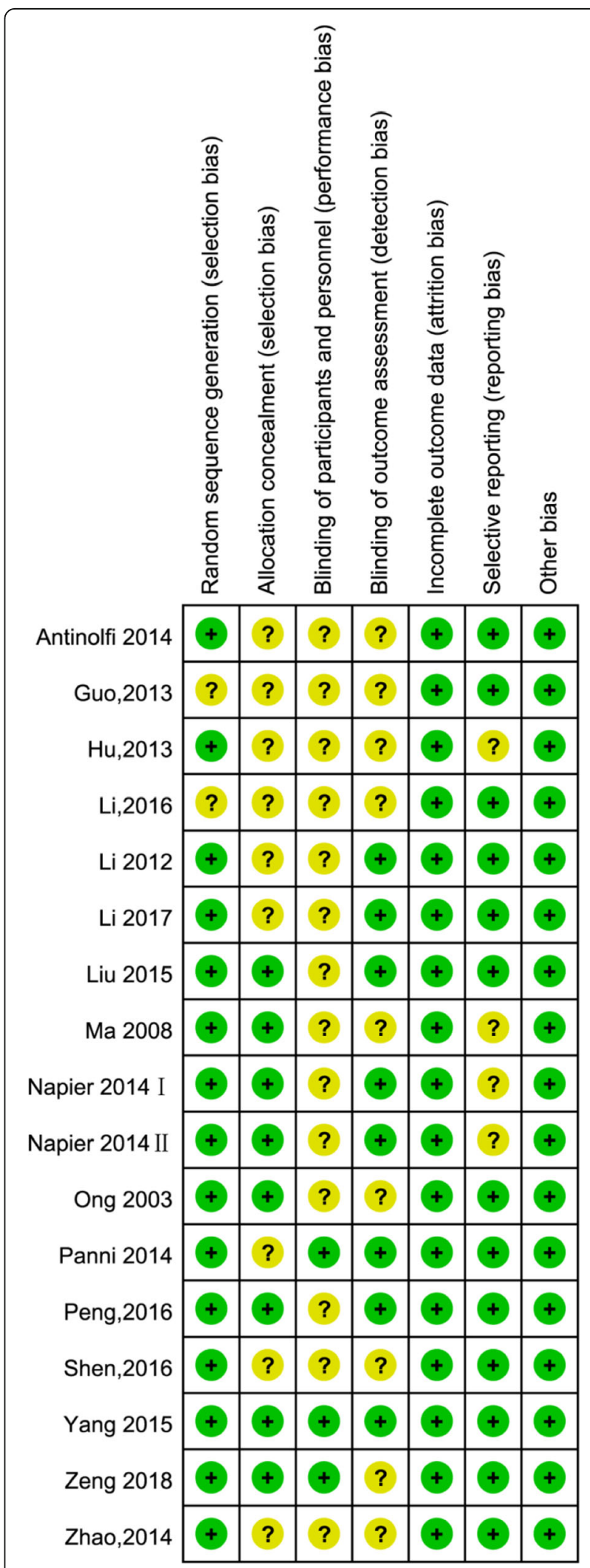

Fig. 2 The risk of bias summary of the included studies (+ represents yes; - represents no; ? represents not clear) 


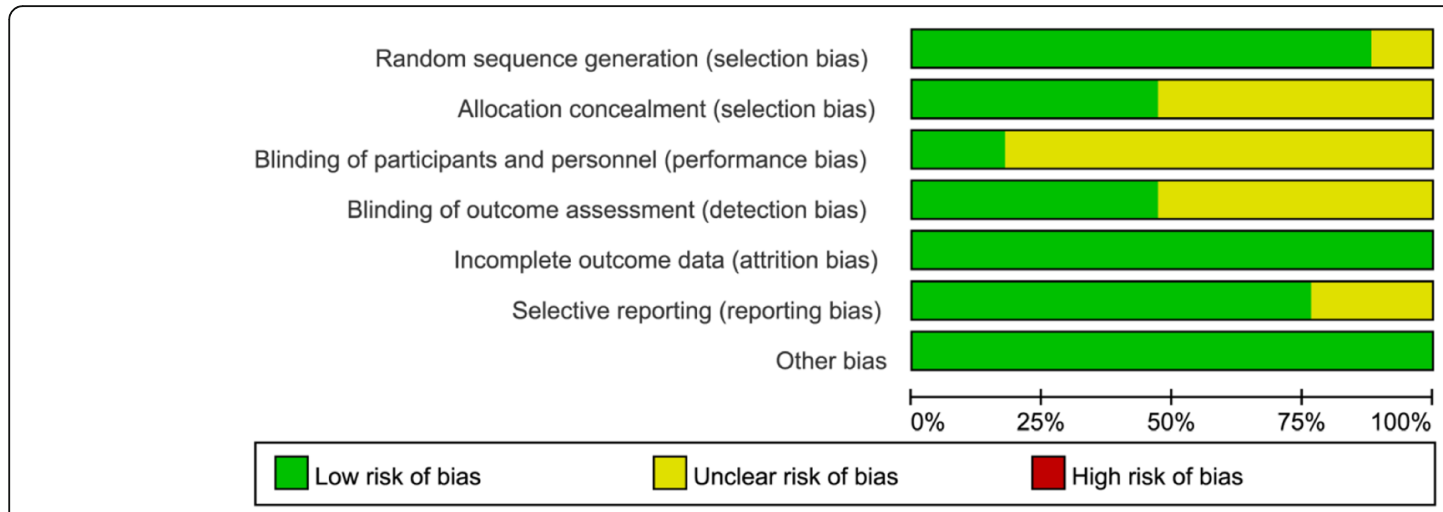

Fig. 3 The risk of bias graph of the included studies

meta-analysis are illustrated in Table 1, while study treatment protocol of RCTs included in the meta-analysis is shown in Table 2.

\section{Quality assessment and risk of bias}

The methodological quality of all the included RCTs was evaluated based on the Cochrane Handbook for Systematic Reviews of Interventions. Fifteen RCTs mentioned the adequate randomization technique including random number list $[21-25,28,34-36,38]$, computer-generated block randomization [20, 26], and sealed random number envelope [27, 42]. Allocation concealment was mentioned in 8 trials [20, 22, 23, $26,27,34,42]$ and unclear in 9 trials [21, 24, 25, 28, 35-39]. Blinding of participants and personnel were mentioned in 3 trials $[23,25,26]$ and unclear in 14 trials [20-22, 24, 26-28, 34-39, 42]. Outcome assessors were blinded in 8 trials $[20-25,34]$, but the blinding in the other 9 trials was unclear [26-28, 3539, 42]. All included studies furnished complete data

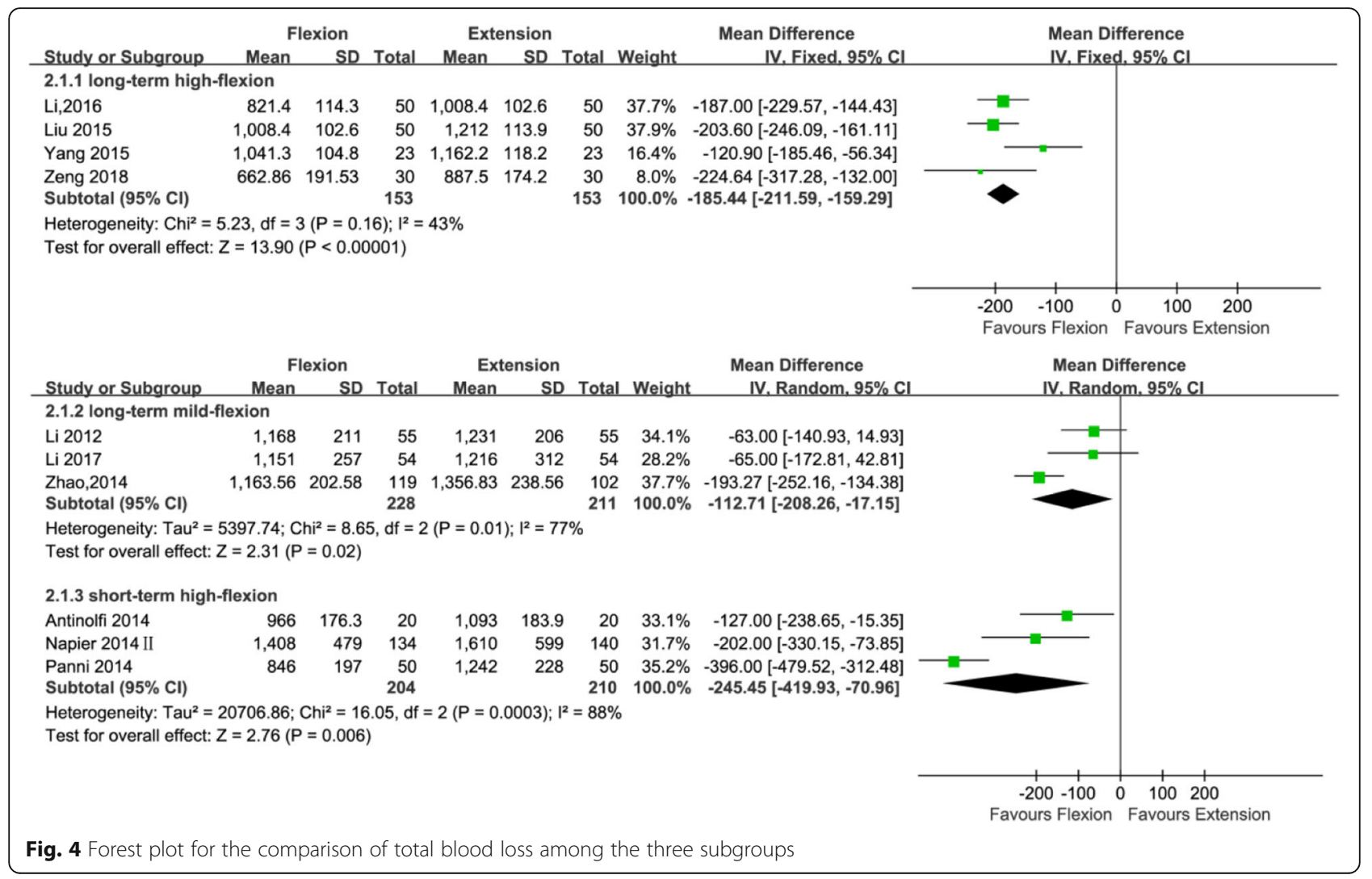


and were considered at low risk for attrition bias. The detailed risk of bias of methodological quality in the eligible RCTs is summarized in Figs. 2 and 3.

\section{Primary outcomes \\ Total blood loss}

Total blood loss was mentioned in 10 studies $(439,306$, and 414 patients in the long-standing mild flexion, long-standing high flexion, and short-standing high flexion groups, respectively). Three studies [21, 24, 36] adopted the postoperative knee management protocols for long-term $(\geq 24 \mathrm{~h})$ mild flexion $\left(\leq 30^{\circ}\right)$, four studies [22, $23,26,39]$ adopted the postoperative knee management protocols for long-term $(\geq 24 \mathrm{~h})$ high flexion $\left(>30^{\circ}\right)$, and three studies $[20,25,28]$ adopted the postoperative knee management protocols for short-term $(<24 \mathrm{~h})$ high flexion $\left(>30^{\circ}\right)$. Subgroup analysis showed significant reduction in total blood loss was found using a long-term $(\geq 24 \mathrm{~h}$ ) mild flexion $\left(\leq 30^{\circ}\right)$ protocol $(\mathrm{MD}=-112.76 ; 95 \% \mathrm{CI},-208.26$ to $\left.-17.15 ; P=0.02 ; I^{2}=77 \%\right)$; significant reduction in total blood loss was also found using a long-term $(\geq 24 \mathrm{~h})$ high flexion $\left(>30^{\circ}\right)$ protocol $(\mathrm{MD}=-185.44 ; 95 \% \mathrm{CI}$, 211.59 to $\left.-159.29 ; P<0.00001 ; I^{2}=43 \%\right)$ and using a short-term $(<24 \mathrm{~h})$ high flexion $\left(>30^{\circ}\right)$ protocol $(\mathrm{MD}=-$ 245.45; $95 \% \mathrm{CI},-419.93$ to $\left.-70.96 ; P=0.006 ; I^{2}=88 \%\right)$ (Fig. 4 and Table 3).

\section{Hidden blood loss}

Eight studies with a total of 845 patients reported the outcome of hidden blood loss $(439,246$, and 160

Table 3 Results of subgroup analyses based on diverse postoperative knee flexion protocols

\begin{tabular}{|c|c|c|c|c|c|c|c|c|c|}
\hline \multirow{2}{*}{$\begin{array}{l}\text { Clinical } \\
\text { results }\end{array}$} & \multirow{2}{*}{$\begin{array}{l}\text { No. } \\
\text { of } \\
\text { trials }\end{array}$} & \multicolumn{3}{|c|}{ No. of participants } & \multirow[t]{2}{*}{ MD/RD } & \multirow[t]{2}{*}{$95 \% \mathrm{Cl}$} & \multirow[t]{2}{*}{$P$ value } & \multirow{2}{*}{$\begin{array}{l}\text { Heterogeneity } \\
p^{2}\end{array}$} & \multirow[t]{2}{*}{ Model } \\
\hline & & Flexion & Extension & $\overline{\text { Total }}$ & & & & & \\
\hline \multicolumn{10}{|c|}{ Total blood loss } \\
\hline LH group & 4 & 153 & 153 & 306 & $-185.44^{a}$ & -211.59 to -159.29 & $<0.00001$ & 43 & Fixed \\
\hline LM group & 3 & 228 & 211 & 439 & $-112.76^{\mathrm{a}}$ & -208.26 to -17.15 & 0.02 & $77^{*}$ & Random \\
\hline SH group & 3 & 204 & 210 & 414 & $-245.45^{a}$ & -419.93 to -70.96 & 0.006 & $88^{*}$ & Random \\
\hline \multicolumn{10}{|c|}{ Hidden blood loss } \\
\hline LH group & 3 & 123 & 123 & 246 & $-95.77^{\mathrm{a}}$ & -138.21 to -53.32 & $<0.00001$ & $85^{*}$ & Random \\
\hline LM group & 3 & 228 & 211 & 439 & $-83.70^{a}$ & -186.28 to 18.88 & 0.11 & $98^{*}$ & Random \\
\hline SH group & 2 & 80 & 80 & 160 & $-196.35^{a}$ & -259.06 to -133.64 & $<0.00001$ & $87^{*}$ & Random \\
\hline \multicolumn{10}{|c|}{ Blood transfusion requirement } \\
\hline LH group & 6 & 232 & 229 & 461 & $-0.08^{b}$ & -0.14 to -0.03 & 0.003 & 40 & Fixed \\
\hline LM group & 2 & 70 & 70 & 140 & $7.00^{b}$ & 4.77 to 9.23 & 0.02 & 0 & Fixed \\
\hline SH group & 2 & 84 & 84 & 168 & $0.02^{b}$ & -0.07 to 0.12 & 0.62 & 0 & Fixed \\
\hline \multicolumn{10}{|c|}{ ROM (1 week after operation) } \\
\hline LH group & 1 & 30 & 30 & 60 & 13.00 & 9.42 to 16.58 & $<0.00001$ & NA & - \\
\hline LM group & 4 & 258 & 241 & 499 & $4.75^{\mathrm{a}}$ & 3.10 to 6.40 & $<0.00001$ & 43 & Fixed \\
\hline SH group & 3 & 205 & 208 & 413 & $2.63^{\mathrm{a}}$ & -2.80 to 8.06 & 0.34 & $93^{*}$ & Random \\
\hline \multicolumn{10}{|l|}{ DVT } \\
\hline LH group & 6 & 232 & 229 & 461 & $0.00^{\mathrm{b}}$ & -0.02 to 0.02 & 1 & 0 & Fixed \\
\hline LM group & 4 & 258 & 241 & 499 & $0.00^{\mathrm{b}}$ & -0.02 to 0.02 & 1 & 0 & Fixed \\
\hline SH group & 4 & 175 & 179 & 354 & $0.00^{b}$ & -0.03 to 0.03 & 0.98 & 0 & Fixed \\
\hline \multicolumn{10}{|c|}{ Wound-related infection } \\
\hline LH group & 6 & 232 & 229 & 461 & $0.01^{b}$ & -0.03 to 0.05 & 0.67 & 0 & Fixed \\
\hline LM group & 3 & 204 & 187 & 391 & $0.00^{\mathrm{b}}$ & -0.02 to 0.02 & 1 & 0 & Fixed \\
\hline SH group & 4 & 224 & 230 & 454 & $-0.00^{b}$ & -0.03 to 0.02 & 0.74 & 0 & Fixed \\
\hline
\end{tabular}

Data in italics indicate a statistically significant $P$ value

Abbreviations: $L H$ long-term ( $\geq 24 \mathrm{~h}$ ) high flexion $\left(>30^{\circ}\right), L M$ long-term $(\geq 24 \mathrm{~h})$ mild flexion $\left(\leq 30^{\circ}\right)$, SH short-term $(<24 \mathrm{~h})$ high flexion $\left(>30^{\circ}\right)$, $C l$ confidence interval, $N A$ not applicable

*Heterogeneity was statistically significant

a Mean difference (MD)

${ }^{\mathrm{b}}$ Risk difference (RD) 


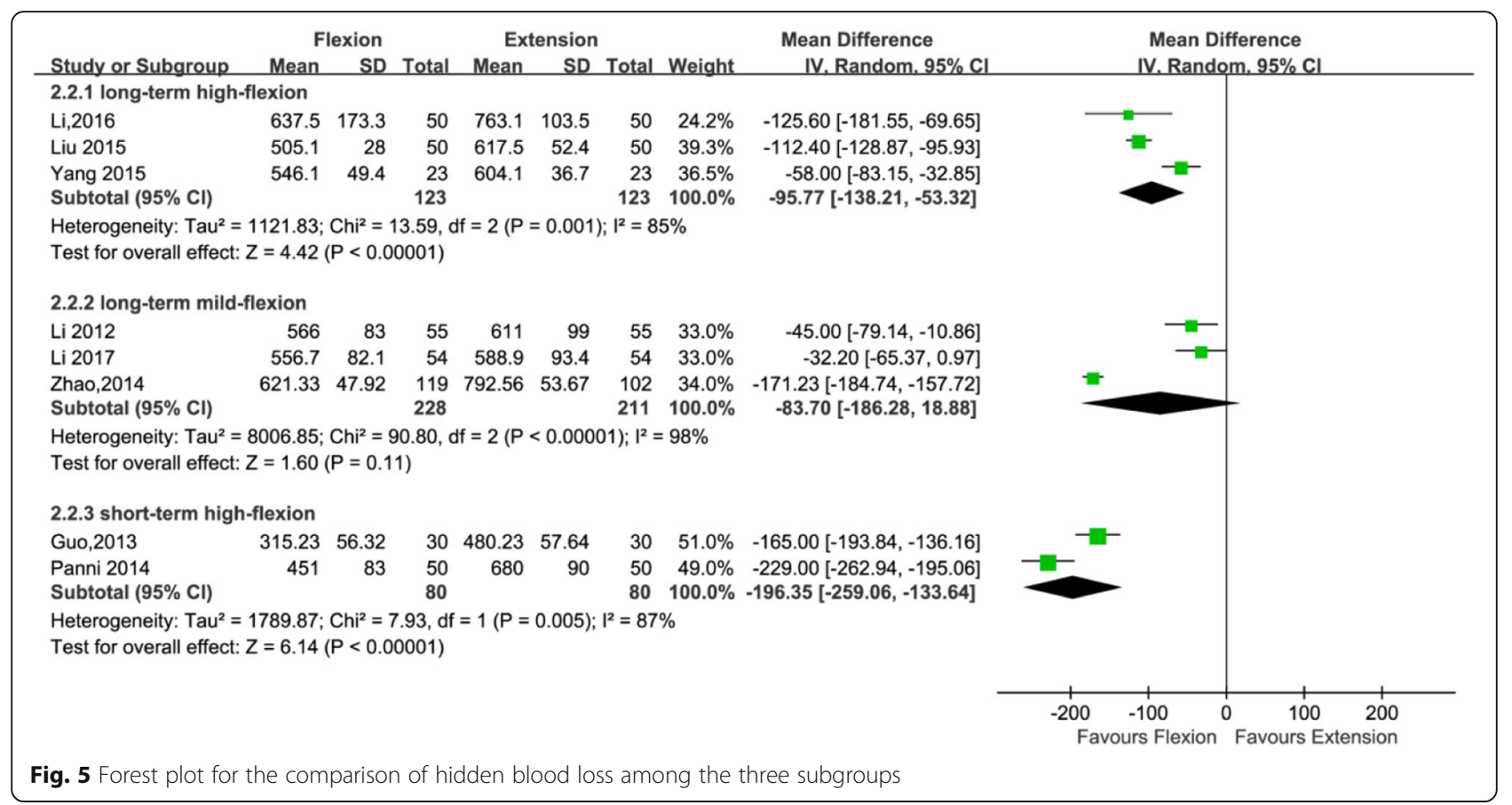

patients in the long-standing mild flexion, long-standing high flexion, and short-standing high flexion groups, respectively). Three studies adopted [21, $24,36]$ the postoperative knee management protocols for long-term $(\geq 24 \mathrm{~h})$ mild flexion $\left(\leq 30^{\circ}\right)$, three studies $[22,23$, 39] adopted the postoperative knee management protocols for long-term $\left(\geq 24 \mathrm{~h}\right.$ ) high flexion $\left(>30^{\circ}\right)$, and two studies $[25,37]$ adopted the postoperative knee management protocols for short-term $(<24 \mathrm{~h})$ high flexion $\left(>30^{\circ}\right)$. The subgroup analysis revealed that hidden blood loss can significantly reduce using a long-term $(\geq 24 \mathrm{~h})$ high flexion $\left(>30^{\circ}\right)$ protocol $(\mathrm{MD}=-95.77 ; 95 \% \mathrm{CI}$, 138.21 to $\left.-53.32 ; P<0.00001 ; I^{2}=85 \%\right)$ and using a short-term $(<24 \mathrm{~h})$ high flexion $\left(>30^{\circ}\right)$ protocol (MD $=-196.35 ; 95 \% \mathrm{CI},-259.06$ to $-133.64 ; P<0.00001$; $\left.I^{2}=87 \%\right)$; however, it cannot significantly reduce using a long-term $(\geq 24 \mathrm{~h})$ mild flexion $\left(\leq 30^{\circ}\right)$ protocol $(\mathrm{MD}=-83.70 ; 95 \% \mathrm{CI},-186.28$ to $18.88 ; P=$ $0.11 ; I^{2}=98 \%$ ) (Fig. 5 and Table 3 ).

\section{Blood transfusion requirement}

Ten studies with a total of 769 patients provided the data of blood transfusion requirement $(168,461$, and 140 patients in the long-standing mild flexion, long-standing high flexion, and short-standing high flexion groups, respectively). Two studies adopted $[24,34]$ the postoperative knee management protocols for long-term $(\geq 24 \mathrm{~h})$ mild flexion $\left(\leq 30^{\circ}\right)$, six studies [22, 23, 26, 27, 34, 39] adopted the postoperative knee management protocols for long-term $(\geq 24 \mathrm{~h})$ high flexion $\left(>30^{\circ}\right)$, and two studies
$[25,42]$ adopted the postoperative knee management protocols for short-term $(<24 \mathrm{~h})$ high flexion $\left(>30^{\circ}\right)$. Subgroup analysis that showed no significant reductions in blood transfusion requirement was found when the knee was fixed in high flexion $\left(>30^{\circ}\right)$ for $<24 \mathrm{~h}(\mathrm{RD}=$ 0.02; $95 \% \mathrm{CI},-0.07$ to $0.12 ; P=0.62 ; I^{2}=0 \%$; however, significant reductions in blood transfusion requirement was found when the knee was fixed in high flexion $\left(>30^{\circ}\right)$ for $\geq 24 \mathrm{~h}$ (RD $=-0.08$; 95\%CI, -0.14 to $-0.03 ; P=0.003$; $\left.I^{2}=40 \%\right)$ and when the knee was fixed in mild flexion ( $\leq$ $30^{\circ}$ ) for $\geq 24 \mathrm{~h}(\mathrm{RD}=7.00 ; 95 \% \mathrm{CI}, 4.77$ to 9.23 ; $P=0.02$; $I^{2}=0 \%$ ) (Fig. 6 and Table 3).

\section{Secondary outcomes ROM at 1 week after operation}

Data from eight studies including 972 patients were available for ROM at 1 week after operation $(499,60$, and 413 patients in the long-standing mild flexion, long-standing high flexion, and short-standing high flexion groups, respectively). Four studies [21, 24, 34, 36] adopted the postoperative knee management protocols for long-term $(\geq 24 \mathrm{~h})$ mild flexion $\left(\leq 30^{\circ}\right)$; one study adopted the postoperative long-term $(\geq 24 \mathrm{~h})$ high flexion $\left(>30^{\circ}\right)$ protocols; and three studies [25, 35, 38 ] adopted the postoperative knee management protocols for short-term $(<24 \mathrm{~h})$ high flexion $\left(>30^{\circ}\right)$. Subgroup analysis that showed no significant improvements in ROM at 1 week after operation was found when the knee was fixed in high flexion $\left(>30^{\circ}\right)$ for $<24 \mathrm{~h}(\mathrm{MD}=2.63 ; 95 \% \mathrm{CI},-2.80$ to $8.06 ; P=$ 


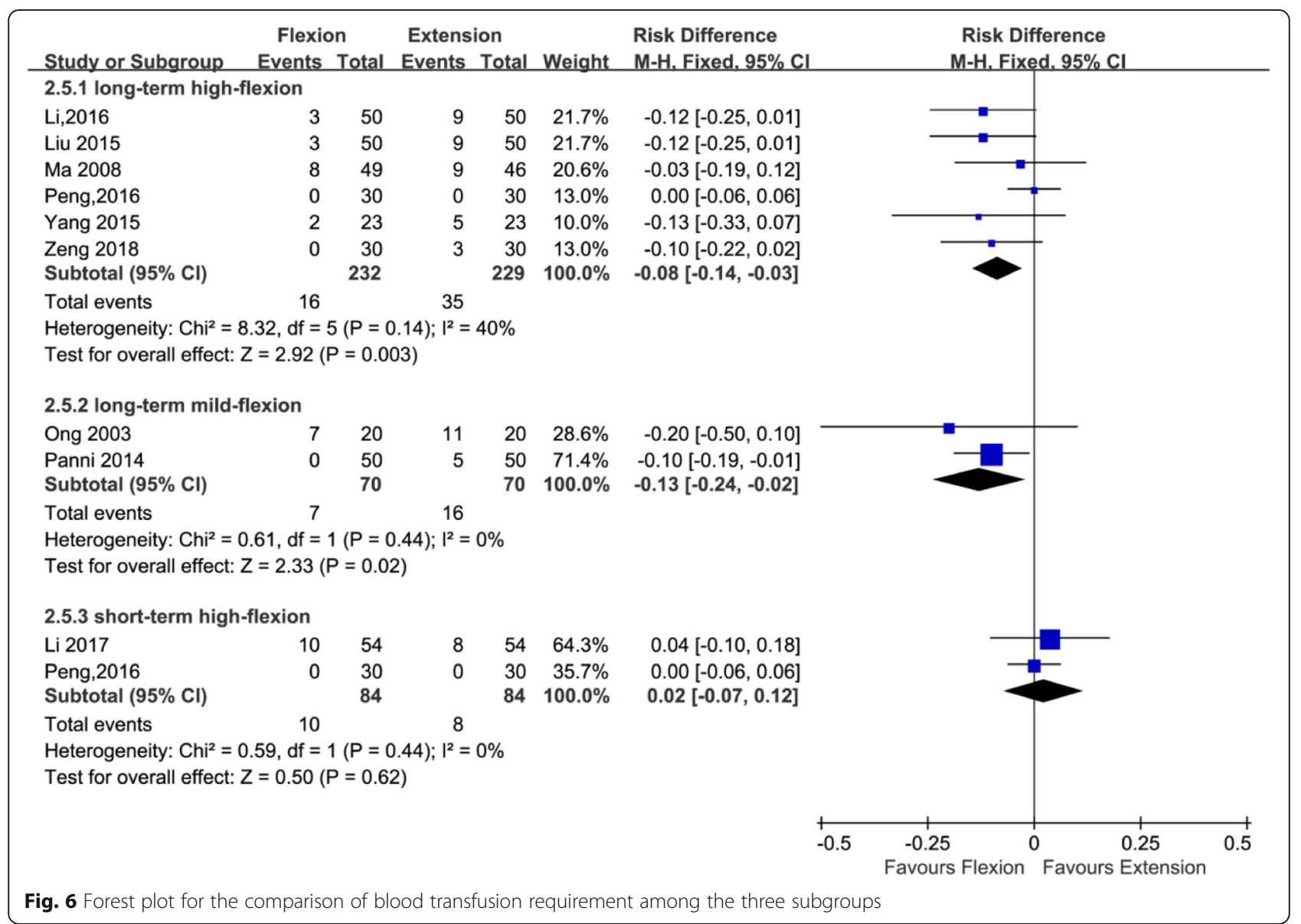

0.34; $I^{2}=93 \%$ ); however, significant improvements in $\mathrm{ROM}$ at 1 week after operation was found when the knee was fixed in high flexion $\left(>30^{\circ}\right)$ for $\geq 24 \mathrm{~h}(\mathrm{MD}=13.00$; 95\%CI, 9.42 to $16.58 ; P<0.00001 ; I^{2}$ not applicable) and when the knee was fixed in mild flexion $\left(\leq 30^{\circ}\right)$ for $\geq 24 \mathrm{~h}$ $\left(\mathrm{MD}=4.75 ; 95 \% \mathrm{CI}, 3.10\right.$ to $\left.6.40 ; P<0.00001 ; I^{2}=43 \%\right)$ (Fig. 7 and Table 3).

\section{DVT}

Fourteen studies with a total of 1314 patients reported the outcome of DVT $(499,461$, and 354 patients in the long-standing mild flexion, long-standing high flexion, and short-standing high flexion groups, respectively). Four studies [21, 24, 34, 36] adopted the postoperative knee management protocols for long-term $(\geq 24 \mathrm{~h})$ mild flexion $\left(\leq 30^{\circ}\right)$, six studies [22, $23,26,27,34,39$ ] adopted the postoperative knee management protocols for long-term $(\geq 24 \mathrm{~h})$ high flexion $\left(>30^{\circ}\right)$, and four studies $[20,25,28,42]$ adopted the postoperative knee management protocols for short-term $(<24 \mathrm{~h})$ high flexion $\left(>30^{\circ}\right)$. The subgroup analysis revealed that DVT cannot significantly reduce using a long-term $(\geq 24 \mathrm{~h})$ high flexion $\left(>30^{\circ}\right)$ protocol $(\mathrm{RD}=0.00 ; 95 \% \mathrm{CI},-0.02$ to $0.02 ; P=1$; $\left.I^{2}=0 \%\right)$ and using a short-term $(<24 \mathrm{~h})$ high flexion $\left(>30^{\circ}\right)$ protocol $(\mathrm{RD}=0.00 ; 95 \% \mathrm{CI},-0.03$ to 0.03 ; $\left.P=0.98 ; I^{2}=0 \%\right)$ and that it cannot also significantly reduce using a long-term $(\geq 24 \mathrm{~h})$ mild flexion $\left(\leq 30^{\circ}\right)$ protocol $\left(\mathrm{RD}=0.00 ; 95 \% \mathrm{CI},-0.02\right.$ to $0.02 ; P=1 ; I^{2}=$ 0\%) (Fig. 8 and Table 3).

\section{Wound-related infection}

Thirteen studies with a total of 1306 patients provided the data of wound-related infection (391, 461, and 454 patients in the long-standing mild flexion, long-standing high flexion, and short-standing high flexion groups, respectively). Three studies $[21,34,36]$ adopted the postoperative knee management protocols for long-term $(\geq$ $24 \mathrm{~h}$ ) mild flexion $\left(\leq 30^{\circ}\right)$, four studies $[22,23,26,27,34$, 39 ] adopted the postoperative knee management protocols for long-term $\left(\geq 24 \mathrm{~h}\right.$ ) high flexion $\left(>30^{\circ}\right)$, and four studies $[20,25,28,42]$ adopted the postoperative knee management protocols for short-term $(<24 \mathrm{~h})$ high flexion $\left(>30^{\circ}\right)$. The subgroup analysis revealed that 


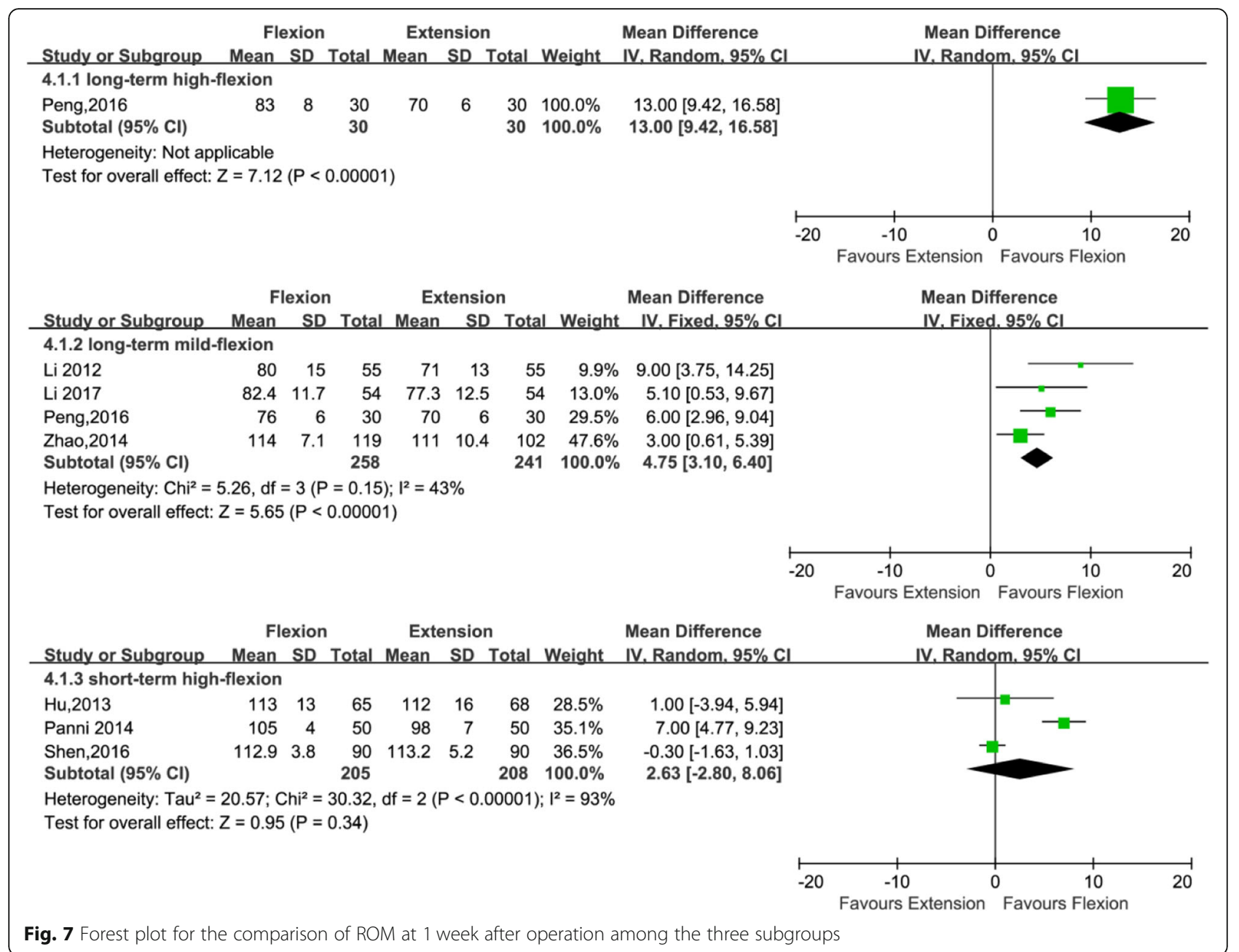

wound-related infection cannot significantly reduce using a long-term $(\geq 24 \mathrm{~h})$ high flexion $\left(>30^{\circ}\right)$ protocol (RD $=0.01 ; 95 \% \mathrm{CI},-0.03$ to $\left.0.05 ; P=0.67 ; I^{2}=0 \%\right)$ and using a short-term $(<24 \mathrm{~h})$ high flexion $\left(>30^{\circ}\right)$ protocol $\left(\mathrm{RD}=-0.00 ; 95 \% \mathrm{CI},-0.03\right.$ to $\left.0.02 ; P=0.74 ; I^{2}=0 \%\right)$ and that it can also not dramatically reduce using a long-term $(\geq 24 \mathrm{~h})$ mild flexion $\left(\leq 30^{\circ}\right)$ protocol $(\mathrm{RD}=$ $0.00 ; 95 \% \mathrm{CI},-0.02$ to $0.02 ; P=1 ; I^{2}=0 \%$ ) (Fig. 9 and Table 3).

\section{Publication bias}

Four funnel plots based on total blood loss, blood transfusion requirement, DVT, and wound-related infection was used to assess publication bias and demonstrated minimal asymmetry and a few outliers, indicating minimal evidence of publication bias (Fig. 10)

\section{Discussion}

This meta-analysis compared the effect of different postoperative knee flexion protocols on patient's outcomes after primary TKA. To our knowledge, this is the first meta-analysis of RCTs that evaluated the effectiveness and safety based on both the degree of knee flexion and duration of knee flexion following primary TKA. The most important finding of the present study is that long-term $(\geq 24 \mathrm{~h})$ high flexion $\left(>30^{\circ}\right)$ protocol could not only significantly reduce total blood loss, hidden blood loss, and transfusion requirements but could also effectively improve ROM at 1 week after operation; short-term $(<24 \mathrm{~h})$ high flexion $\left(>30^{\circ}\right)$ protocol could significantly reduce total blood loss and hidden blood loss; long-term $(\geq 24 \mathrm{~h})$ mild flexion $\left(\leq 30^{\circ}\right)$ significantly reduce total blood loss and transfusion requirements and improve ROM at 1 week after operation. There was no significant difference with respect to the incidence of wound-related infection and DVT between the three flexion groups during the follow-up period.

Blood loss in TKA is a significant problem for the orthopedic surgeon who can use a variety of perioperative methods to minimize it and possibly reduce 


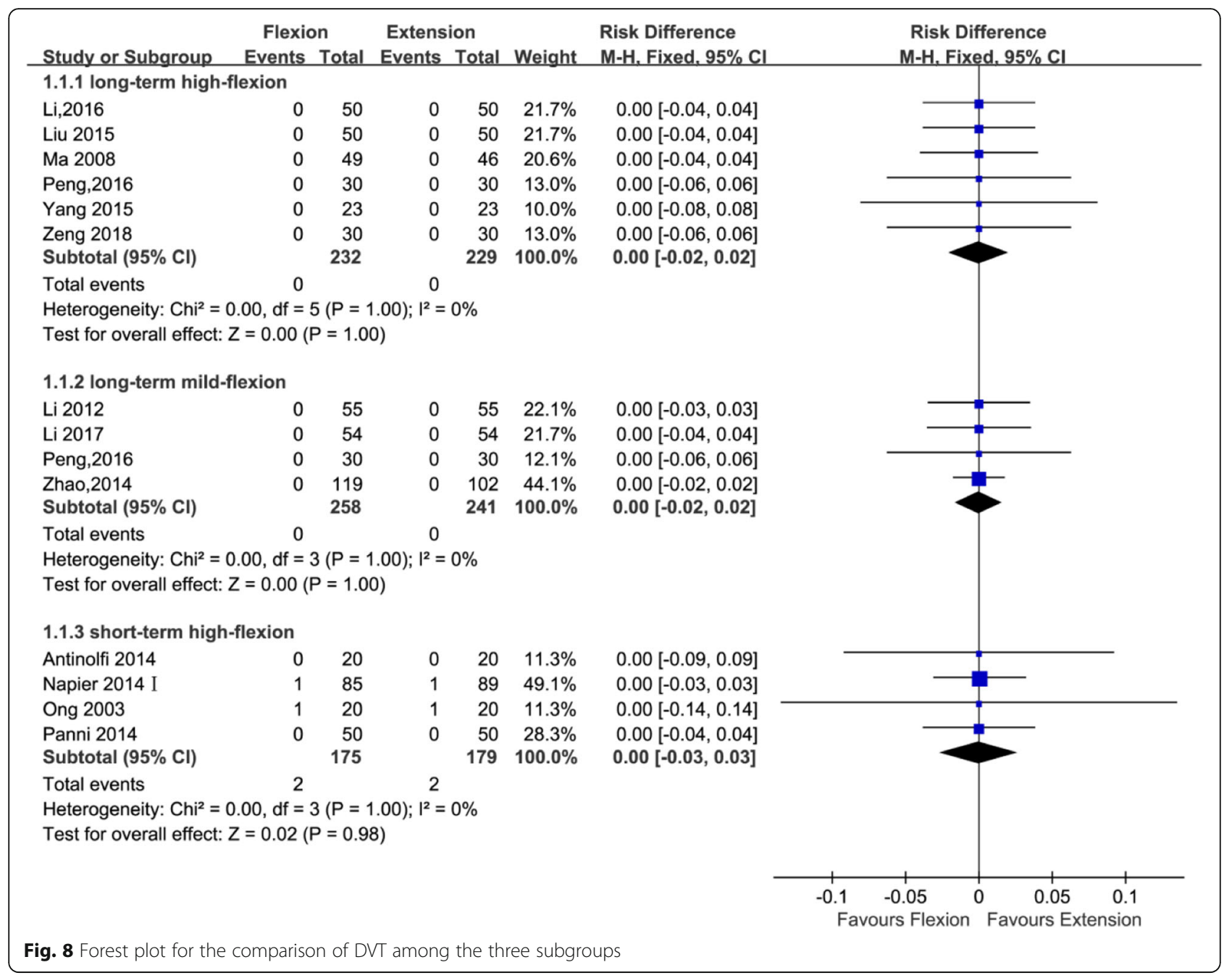

any related side effects. Two previous meta-analyses have shown that compared to knee full extension, postoperative flexion position is a simple and cost-effective approach to reduce blood loss and transfusion requirements and increase ROM in the early postoperative period after primary TKA $[7,30]$. Theoretically, the knee position was closely related to the tension of popliteal vessels. The postoperative knee flexion, to some extent, lowered the tension of popliteal vessels, which can increase venous return [24]. This process takes turns to reduce total blood loss and hidden blood loss including blood extravasation into the tissues and residual blood in the joint, which can distinctly lower intraarticular pressure and capsular tension, ultimately accelerating range of motion restoration $[21,23,25,33]$. However, there remains no consensus upon whether it is specific knee position and duration of knee flexion which conduces most to the benefits seen with postoperative knee flexion protocol. Long-term knee flexion may be beneficial to reduce blood loss [25]. Faldini et al. [31] performed a systematic review of seven studies to assess the effect of postoperative limb position on outcomes after TKA and found that a 48-72 h postoperative knee flexion appears to be beneficial to reducing blood loss and increasing ROM following TKA; short-term flexion protocol failed to alter these parameters. Mild flexion may be less effective for blood loss reduction because it leads to lower compression on the blood vessel with lower effect on peripheral blood circulation [25]. However, Wu et al. [32] performed a meta-analysis of nine RCTs to compare the effectiveness of different limb positions in primary TKA and found that knee mild flexion (< $60^{\circ}$ ) protocol is significantly beneficial with hidden blood loss after TKA compared with knee high flexion $\left(\geq 60^{\circ}\right)$; knee high flexion $\left(\geq 60^{\circ}\right)$ protocol is superior to mild flexion $\left(<60^{\circ}\right)$ protocol in reducing 


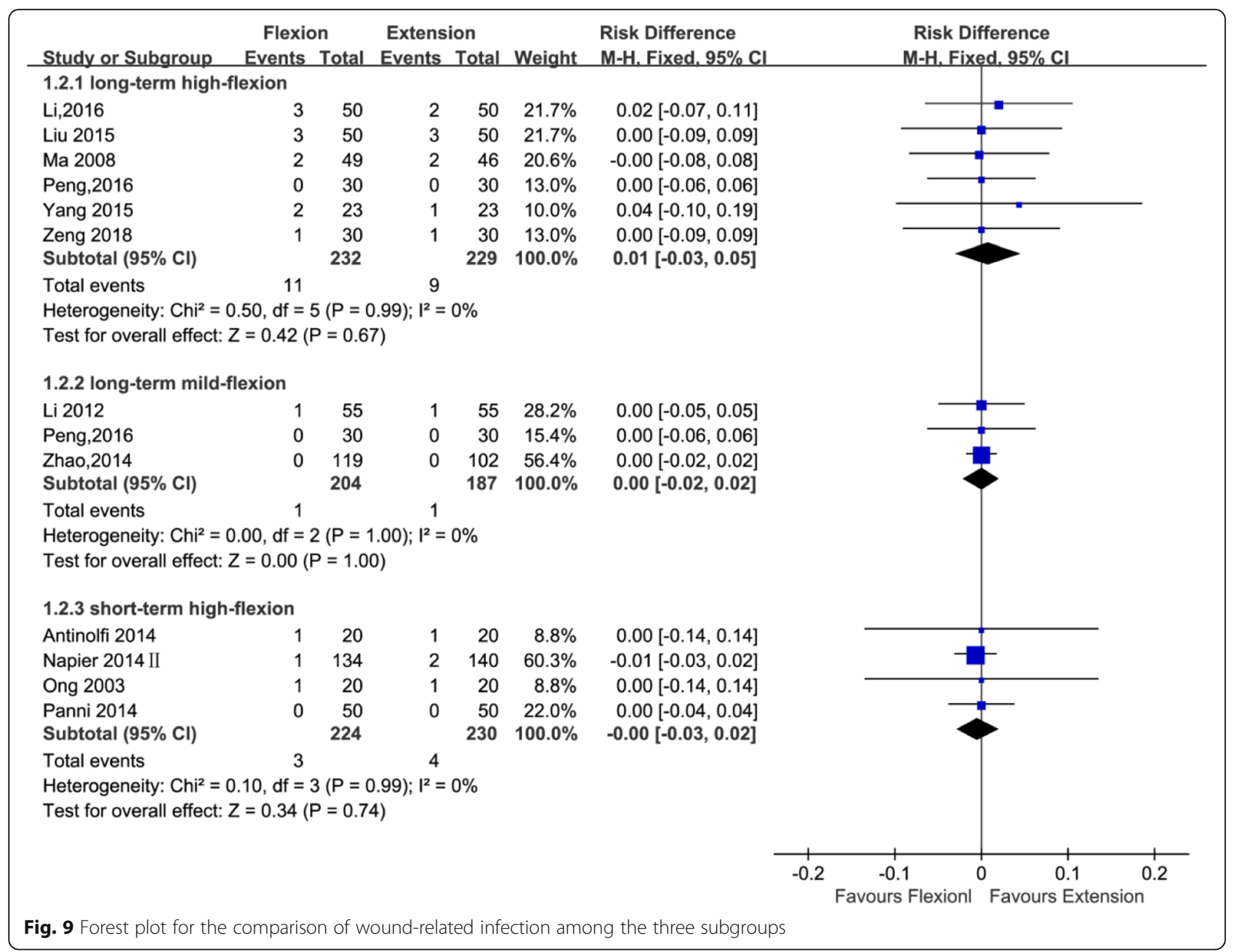

blood transfusion requirements and improving ROM following TKA. De Fine et al. [33] conducted a randomized controlled trial of 62 patients to understand the optimal degree of flexion required to improve functional outcomes and found that no significant differences were found between the high flexion $\left(70^{\circ}\right)$ and mild flexion $\left(30^{\circ}\right)$ group in terms of blood loss, transfusion requirements, and ROM after TKA. In the present meta-analysis, although the differences in total blood loss between three flexion protocols were unclear, subgroup analysis suggested that long-term $(\geq 24 \mathrm{~h})$ high flexion $\left(>30^{\circ}\right)$ protocol could provide extra benefits compared with short-term $(<24 \mathrm{~h})$ high flexion $\left(>30^{\circ}\right)$ protocol in regard to ROM at 1 week after operation and compared with long-term $(\geq 24 \mathrm{~h})$ mild flexion $\left(\leq 30^{\circ}\right)$ protocol regarding hidden blood loss and blood transfusion requirements. Nevertheless, there was significant heterogeneity in terms of total blood loss and hidden blood loss in the three flexion subgroups. Thus, we used a random effects model to analyze these statistical data. But, we speculate that the observed heterogeneity was mainly caused by the clinical differences, such as differences in the operating skill of different surgeons and differences in the application of the tourniquet, drainage, and tranexamic acid.

Wound-related infection is one of complication following TKA. Johnson has reported that keeping the knee in flexion position following TKA may maximize wound complications by reducing oxygen tension on the skin edges [43]. However, the decreased oxygen tension at the skin edges secondary to postoperative mild knee flexion should be compromised by the increased local perfusion and oxygen tension favored by the reduction in knee swelling [21, 25]. Subgroup analysis in this meta-analysis showed that the significant difference in the rate of wound-related infection was not found between three flexion protocols. A greater degree of knee flexion may curve popliteal veins and hinder venous return [44]. Obstructed venous return resulted from knee flexion should increase the risk of DVT [24]. But, subgroup analysis of this 

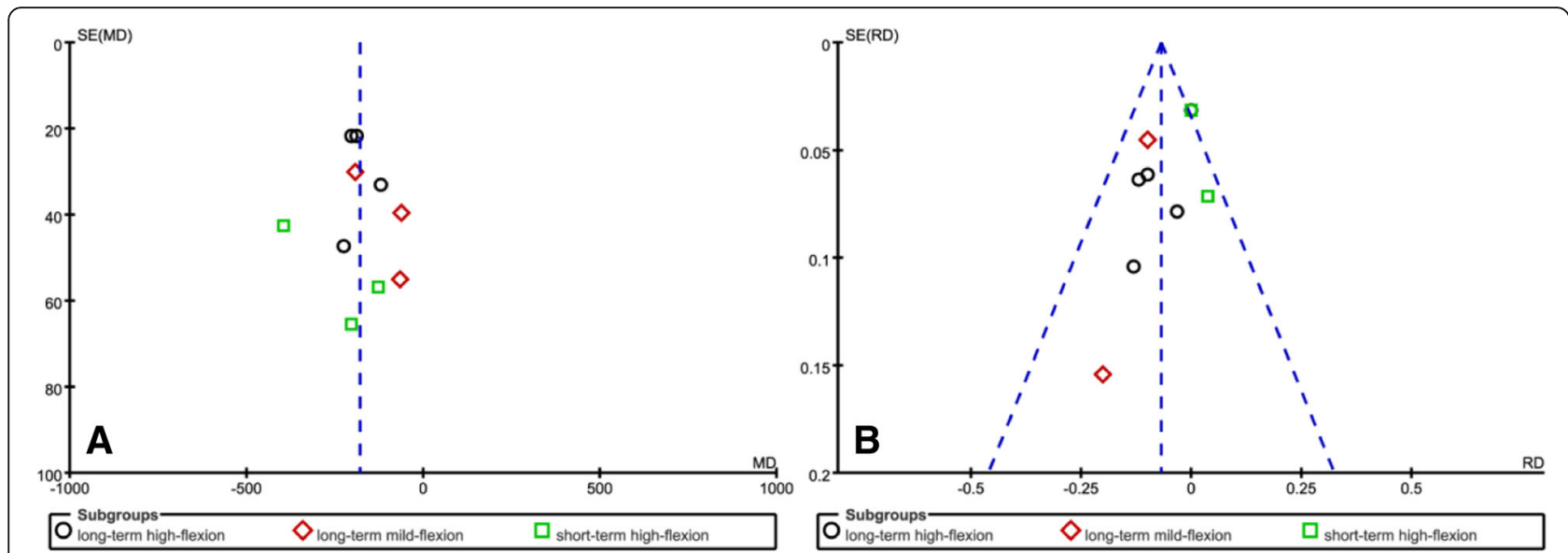

$\mathrm{O}_{\text {long-term high-flexion }}^{\text {Subgroups }} \diamond_{\text {long-term mild-flexion }} \quad \square_{\text {short-term high-flexion }}$
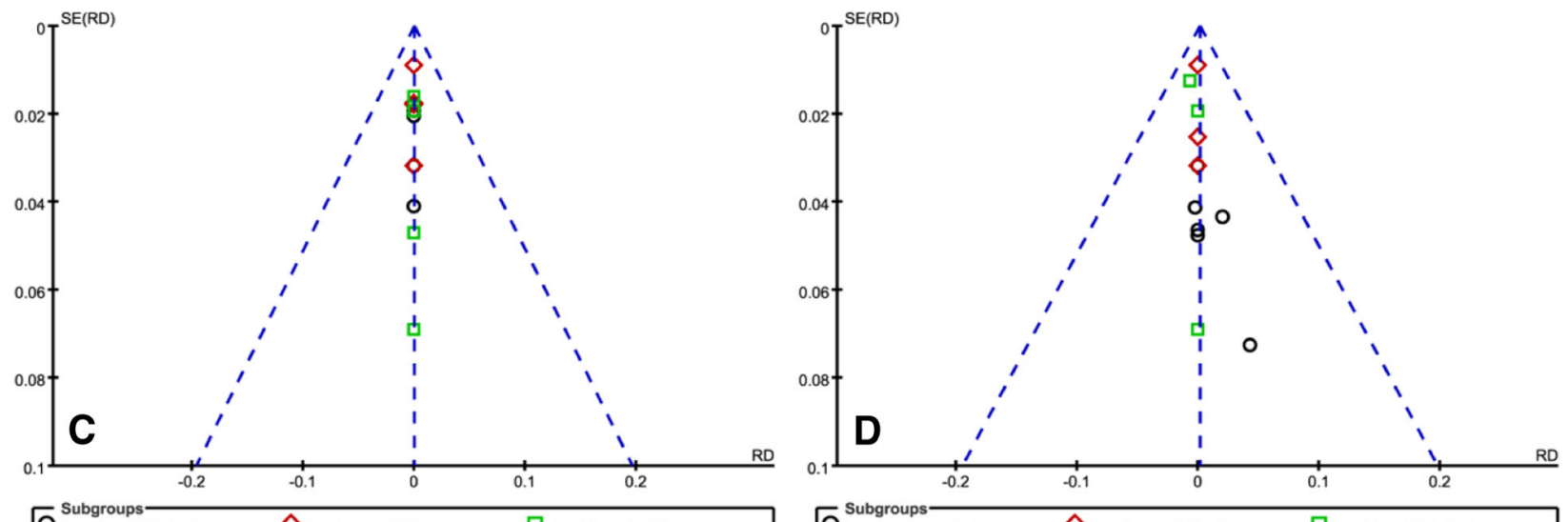

$\mathrm{O}_{\text {long-term high-flexion }}^{\text {Subgroups }}$

$\diamond_{\text {Iong-term mild-flexion }}$

$\square$ short-term high-flexion

${ }_{\mathrm{O}}^{\text {Song-term high-flexion }}$ Subgrous

$\diamond_{\text {Iong-term mild-flexion }}$

$\square_{\text {short-term high-flexion }}$

Fig. 10 Funnel plot of the current meta-analysis. Total blood loss (a). Blood transfusion requirement (b). DVT (c). Wound-related infection (d)

meta-analysis found that the no significant difference in the rate of DVT was not found between different flexion protocols.

Our meta-analysis has several advantages compared with the meta-analysis previously published by Faldini et al. [31], Fu et al. [7], Jiang et al. [30], and Wu et al. [32]. First, our study included one recent high-quality RCT by Zeng et al. [26] and six RCTs [34-39] written in Chinese excluded by previous reviews, which would have reduced statistical bias and publication bias. Second, our study also excluded one [29] quasi-randomized trials and two earlier trials lacking of specific data in knee flexion angle $[45,46]$, and subgroup analysis based on both the degree of knee flexion and duration of knee flexion was conducted, bringing about more precise conclusions. Third, we used a funnel plot to assess publication bias when the number of trials reporting the primary outcomes was ten or more, and these results indicated that publication bias was well controlled. Therefore, these factors strengthen the availability of our findings.
However, our meta-analysis also has some limitations. First, the majority of RCTs we included were characterized by their small sample size and the number of RCTs included in each knee flexion subgroups remains too small, which might increase the likelihood of misestimation magnitude of the intervening effect. Second, heterogeneity among the included studies was unavoidable because of transfusion trigger differences, differences in the operating skill of different surgeons, and differences in the application of the tourniquet, drainage, anticoagulant, and tranexamic acid. Third, the follow-up duration of DVT in the included studies was different, which may have influenced the rate of postoperative DVT. Fourth, we failed to obtain partial original data from some included study authors by e-mail, such as drainage blood loss, length of stay, hospitalization costs, which hinder us from fully analyzing these statistical data between different flexion protocols.

\section{Conclusion}

This meta-analysis showed that the long-term $(\geq 24 \mathrm{~h})$ high flexion $\left(>30^{\circ}\right)$ protocol could be optimal limb management to reduce blood loss and blood 
transfusion requirements and facilitate early postoperative rehabilitation exercises in patients after primary TKA without increasing in complication rate. However, considering the defect of the study design, several biases, such as selection bias, performance bias, and detection bias, may lower the hierarchy of evidence quality. So, more well-designed and large-scale RCTs with long-term follow-up that identifies the efficacy and safety of different postoperative knee flexion protocols in patient's outcomes will be needed in the future.

\section{Abbreviations \\ Cl: Confidence interval; DVT: Deep vein thrombosis; MD: Mean difference; PRISMA: Preferred Reporting Items for Systematic Reviews and Meta- Analyses; RCTs: Randomized controlled trials; RD: Risk difference; ROM: Range of motion; TKA: Total knee arthroplasty}

\section{Acknowledgements}

We are very grateful for many helpful comments by an anonymous reviewer on an earlier version of this manuscript.

\section{Funding}

There is no funding for this article.

\section{Availability of data and materials}

We state that all data generated during the present study are included in this article.

\section{Declarations}

The first author is responsible for misconduct in the research and writing process. The original images, data (including computer database) records, and samples involved in the paper have been saved, Shared and destroyed in accordance with relevant regulations and can accept verification.

\section{Authors' contributions}

HYW and YBL performed the study design. GSY, JHL, and SXZ participated in the literature search and data extraction. HYW, GSY, and JHL were in charge of quality assessment and statistical analysis. HYW was responsible for the manuscript review. All authors read and approved the final manuscript.

\section{Ethics approval and consent to participate}

Not applicable

\section{Consent for publication}

Not applicable

\section{Competing interests}

The authors declare no competing interests.

\section{Publisher's Note}

Springer Nature remains neutral with regard to jurisdictional claims in published maps and institutional affiliations.

Received: 28 September 2018 Accepted: 28 March 2019

Published online: 10 April 2019

\section{References}

1. Lei Y, Xie J, Xu B, Xie X, Huang Q, Pei F. The efficacy and safety of multipledose intravenous tranexamic acid on blood loss following total knee arthroplasty: a randomized controlled trial. Int Orthop. 2017:41:2053-9.

2. Xie J, Ma J, Yao H, Yue C, Pei F. Multiple boluses of intravenous tranexamic acid to reduce hidden blood loss after primary total knee arthroplasty without tourniquet: A Randomized Clinical Trial. J Arthroplasty. 2016;31: 2458-64.

3. Huang Z, Xie X, Li L, Huang Q, Ma J, Shen B, et al. Intravenous and topical tranexamic acid alone are superior to tourniquet use for primary total knee arthroplasty: a prospective, randomized controlled trial. J Bone Joint Surg Am. 2017;99:2053-61.

4. Cankaya D, Della VC. Blood loss and transfusion rates in the revision of unicompartmental knee arthroplasty to total knee arthroplasty are similar to those of primary total knee arthroplasty but are lower compared with the revision total knee arthroplasty. J Arthroplasty. 2016;31:339-41.

5. Seo JG, Moon YW, Park SH, Kim SM, Ko KR. The comparative efficacies of intra-articular and IV tranexamic acid for reducing blood loss during total knee arthroplasty. Knee Surg Sports Traumatol Arthrosc. 2013;21:1869-74.

6. Loftus TJ, Spratling L, Stone BA, Xiao L, Jacofsky DJ. A patient blood management program in prosthetic joint arthroplasty decreases blood use and improves outcomes. J Arthroplasty. 2016;31:11-4.

7. Fu X, Tian P, Li ZJ, Sun XL, Ma XL. Postoperative leg position following total knee arthroplasty influences blood loss and range of motion: a metaanalysis of randomized controlled trials. Curr Med Res Opin. 2016;32:771-8.

8. Lee SY, Chong S, Balasubramanian D, Na YG, Kim TK. What is the ideal route of administration of tranexamic acid in TKA? A randomized controlled trial. Clin Orthop Relat Res. 2017:475:1987-96.

9. Ponnusamy KE, Kim TJ, Khanuja HS. Perioperative blood transfusions in orthopaedic surgery. J Bone Joint Surg Am. 2014;96:1836-44.

10. Jergesen HE, Poss R, Sledge CB. Bilateral total hip and knee replacement in adults with rheumatoid arthritis: an evaluation of function. Clin Orthop Relat Res. 1978:120-8.

11. Tzatzairis TK, Drosos Gl, Kotsios SE, Ververidis AN, Vogiatzaki TD, Kazakos Kl. Intravenous vs topical tranexamic acid in total knee arthroplasty without tourniquet application: a randomized controlled study. J Arthroplasty. 2016; 31:2465-70.

12. Zhou $K$, Ling $T$, Wang $H$, Zhou Z, Shen B, Yang J, et al. Influence of tourniquet use in primary total knee arthroplasty with drainage: a prospective randomised controlled trial. J Orthop Surg Res. 2017;12:172.

13. Wang CG, Sun ZH, Liu J, Cao JG, Li ZJ. Safety and efficacy of intra-articular tranexamic acid injection without drainage on blood loss in total knee arthroplasty: a randomized clinical trial. Int J Surg. 2015;20:1-07.

14. Li T, Zhuang Q, Weng X, Zhou L, Bian Y. Non-continuous versus continuous wound drainage after total knee arthroplasty: a meta-analysis. Int Orthop. 2014;38:361-71.

15. Alcelik IA, Blomfield MI, Diana G, Gibbon AJ, Carrington N, Burr S. A comparison of short-term outcomes of minimally invasive computerassisted vs minimally invasive conventional instrumentation for primary total knee arthroplasty: a systematic review and meta-analysis. J Arthroplasty. 2016;31:410-8.

16. Adie S, Naylor JM, Harris IA. Cryotherapy after total knee arthroplasty a systematic review and meta-analysis of randomized controlled trials. J Arthroplasty. 2010;25:709-15.

17. Wang $H$, Shan $L$, Zeng $H$, Sun M, Hua $Y$, Cai Z. Is fibrin sealant effective and safe in total knee arthroplasty? A meta-analysis of randomized trials. J Orthop Surg Res. 2014;9:36.

18. Zeng WN, Liu JL, Wang FY, Chen C, Zhou Q, Yang L. Low-dose epinephrine plus tranexamic acid reduces early postoperative blood loss and inflammatory response: a randomized controlled trial. J Bone Joint Surg Am. 2018;100:295-304

19. Timlin M, Moroney P, Collins D, Toomey D, O'Byrne J. The $90 / 90$ pillow reduces blood loss after knee arthroplasty: a prospective randomized case control study. J Arthroplasty. 2003;18:765-8.

20. Napier RJ, Bennett D, Mc Conway J, Wilson R, Sykes AM, Doran E, et al. The influence of immediate knee flexion on blood loss and other parameters following total knee replacement. Bone Joint J. 2014;96-B: 201-9.

21. Li B, Wen Y, Liu D, Tian L. The effect of knee position on blood loss and range of motion following total knee arthroplasty. Knee Surg Sports Traumatol Arthrosc. 2012;20:594-9.

22. Liu J, Li YM, Cao JG, Wang L. Effects of knee position on blood loss following total knee arthroplasty: a randomized, controlled study. J Orthop Surg Res. 2015;10:69

23. Yang Y, Yong-Ming L, Pei-jian D, Jia L, Ying-ze Z. Leg position influences early blood loss and functional recovery following total knee arthroplasty: a randomized study. Int J Surg. 2015;23:82-6.

24. Li B, Wang G, Wang Y, Bai L. Effect of two limb positions on venous hemodynamics and hidden blood loss following total knee arthroplasty. J Knee Surg. 2017;30:70-4. 
25. Panni AS, Cerciello S, Vasso M, Del RC. Knee flexion after total knee arthroplasty reduces blood loss. Knee Surg Sports Traumatol Arthrosc. 2014; 22:1859-64.

26. Zeng Y, Si H, Li C, Wu Y, Shen B. Effect of knee flexion position and combined application of tranexamic acid on blood loss following primary total knee arthroplasty: a prospective randomized controlled trial. Int Orthop. 2018;42:529-35.

27. Ma T, Khan RJ, Carey SR, Nivbrant B, Wood DJ. Effect of flexion/extension splintage post total knee arthroplasty on blood loss and range of motion a randomised controlled trial. Knee. 2008;15:15-9.

28. Antinolfi P, Innocenti B, Caraffa A, Peretti G, Cerulli G. Post-operative blood loss in total knee arthroplasty: knee flexion versus pharmacological techniques. Knee Surg Sports Traumatol Arthrosc. 2014 22:2756-62

29. Madarevic T, Tudor A, Sestan B, Santic V, Gulan G, Prpic T, et al. Postoperative blood loss management in total knee arthroplasty: a comparison of four different methods. Knee Surg Sports Traumatol Arthrosc. 2011;19:955-9.

30. Jiang C, Lou J, Qian W, Ye C, Zhu S. Impact of flexion versus extension of knee position on outcomes after total knee arthroplasty: a meta-analysis. Arch Orthop Trauma Surg. 2017;137:257-65.

31. Faldini C, Traina F, De Fine M, Pedrini M, Sambri A. Post-operative limb position can influence blood loss and range of motion after total knee arthroplasty: a systematic review. Knee Surg Sports Traumatol Arthrosc. 2015;23:852-9.

32. Wu Y, Yang T, Zeng Y, Si H, Li C, Shen B. Effect of different postoperative limb positions on blood loss and range of motion in total knee arthroplasty: an updated meta-analysis of randomized controlled trials. Int J Surg. 2017; 37:15-23.

33. De Fine M, Traina F, Giavaresi G, Leo E, Sanzarello I, Perna F, et al. Effect of different postoperative flexion regimes on the outcomes of total knee arthroplasty: randomized controlled trial. Knee Surg Sports Traumatol Arthrosc. 2017;25:2972-7.

34. Peng H, Lu Q, Yin D. Efficacy of knee position in reducing blood loss following total knee arthroplasty. Chin J Joint Surg( Electronic Edition). 2016; 10:42-5

35. Hu BQ, Tian SQ, Yang X, Xu ZN, Sun K. Randomized controlled trial of effects of limb positions on blood loss after total knee arthroplasty. Chin J Joint Surg( Electronic Edition). 2013;7:150-3.

36. Zhao X, Tian SQ, Liu JJ, Zou Y, Ji SB, Sun K. The effect of limb position on blood loss following total knee arthroplasty-a randomized controlled trial. Chin J Med. 2014;49:31-4.

37. Guo B, Chen XJ, Guo W. The effect of limb positions on hidden blood loss after primary total knee arthroplasty. Orthopedic J China. 2013;21: 305-6.

38. Shen WS, Ren ZW, Shao J, Li DS, Pan LP, Lou J. Effect of total knee arthroplasty after limb position on postoperative hemorrhage. Chin J Prim Med Pharm. 2016:23:2777-80

39. Li LB, Lang LL, Wang X, Li F, Wang CW. The effect of postoperative knee position on blood loss and function. J Pract Orthopaedics. 2016;22:683-5.

40. Moher D, Liberati A, Tetzlaff J, Altman DG. Preferred reporting items for systematic reviews and meta-analyses: the PRISMA statement. BMJ. 2009; 339:b2535.

41. Egger M, Davey SG, Schneider M, Minder C. Bias in meta-analysis detected by a simple, graphical test. BMJ. 1997;315:629-34.

42. Ong SM, Taylor GJ. Can knee position save blood following total knee replacement? Knee. 2003;10:81-5.

43. Johnson DP. Infection after knee arthroplasty. Clinical studies of skin hypoxia and wound healing. Acta Orthop Scand Suppl. 1993;252:1-48,

44. Li B, Wen Y, Wu H, Qian Q, Lin X, Zhao H. The effect of tourniquet use on hidden blood loss in total knee arthroplasty. Int Orthop. 2009;33:1263-8.

45. Horton TC, Jackson R, Mohan N, Hambidge JE. Is routine splintage following primary total knee replacement necessary? A prospective randomised trial. Knee. 2002;9:229-31.

46. Zenios M, Wykes $P$, Johnson DS, Clayson AD, Kay P. The use of knee splints after total knee replacements. Knee. 2002:9:225-8.

Ready to submit your research? Choose BMC and benefit from:

- fast, convenient online submission

- thorough peer review by experienced researchers in your field

- rapid publication on acceptance

- support for research data, including large and complex data types

- gold Open Access which fosters wider collaboration and increased citations

- maximum visibility for your research: over $100 \mathrm{M}$ website views per year

At $\mathrm{BMC}$, research is always in progress.

Learn more biomedcentral.com/submissions 